\title{
Recessão gengival na dentição decídua: relato de caso clínico
}

\author{
Silvana Regina Perez Orrico* \\ Carolina Chan Cirelli* \\ Fabiana Paim Rosa ${ }^{* * *}$ \\ Juliana Teixeira Bacalhau ${ }^{* * *}$
}

\section{Resumo}

Os autores relatam caso de recessão gengival na dentição decídua, uma ocorrência incomum, e discutem aspectos clínicos, fatores determinantes e predisponentes ao aparecimento do problema mucogengival, e o plano de tratamento com medidas interceptativas e preventivas.

Palavras-chave: Recessão gengival. Mordida aberta anterior. Mordida cruzada posterior. Hábito de sucção de chupeta. Deglutição atípica.

\section{INTRODUÇÃO}

A recessão gengival é uma alteração caracterizada pela migração apical da margem gengival. Segundo Stoner e Mazdyasna ${ }^{1}$ a recessão pode ser classificada em verdadeira e pseudorecessão. Na primeira, a migração gengival ultrapassa o limite amelocementário e expõe a raiz; na segunda, há apenas diferença do nível gengival em relação aos dentes homólogos, porém sem exposição radicular.

De ocorrência freqüente em adultos, é pouco evidenciada na dentição decídua, correspondendo à média de $8 \%$ em crianças com idade entre 8 e 12 anos, localizando-se principalmente na região de incisivos inferiores. ${ }^{2,3,4}$ Em con- trapartida, Harrison e colaboradores ${ }^{5}$ observaram ser relativamente comum encontrar pseudorecessão em crianças durante a fase de dentição mista e com mordida cruzada (54\%).

Quando presente em indivíduos muito jovens, a recessão gengival pode estar relacionada a hábitos bucais, como sucção digital e de chupeta, ou ainda à presença de mordida aberta anterior associada ao selamento labial incompetente. $^{6,7,8}$ Outros autores, como Tatakis e Milledge, ${ }^{9}$ relataram recessão gengival severa em pacientes com retardo mental associado ao autoflagelo, e Sepet e colaboradores ${ }^{10}$ constataram o aparecimento de recessão gengival auto-induzida em crianças de 4 a 6 anos, tendo como

\footnotetext{
* Professora Doutora. Departamento de Diagnóstico e Cirurgia. Faculdade de Odontologia. UNESP/Araraquara Faculdade de Odontologia

Universidade Estadual Paulista

Rua Humaitá, 1680

148.019-03 - Araraquara SP Brasil

Tel.: (16) 201-6377

E-mail: s-orrico@foar.unesp.br

${ }^{* *}$ Doutora em Ortodontia pela Faculdade de Odontologia da UNESP/Araraquara.

${ }^{* * *}$ Professora Doutora. Departamento de Biointeração. Instituto de Ciências da Saúde. UFBA.

${ }^{* * * *}$ Cirurgiā-dentista. Estagiária do Departamento de Diagnóstico e Cirurgia. Faculdade de Odontologia. UNESP/ Araraquara.
} 
etiologia fatores psicológicos, especialmente o estresse.

Outros fatores, como mau posicionamento dentário, especialmente vestibuloversão e giroversão, ${ }^{11,12,13,14}$ espessura da gengiva queratinizada, ${ }^{11}$ inserção alta de freio, ${ }^{1}$ trauma oclusal ${ }^{15}$ e mecânico ${ }^{11,12}$ e discrepância intermaxilar, têm sido considerados. ${ }^{5}$ Alguns autores relacionam-na também à presença de inflamação gengival. ${ }^{11,16,17}$

O tratamento da recessão pode ser curativo ou preventivo, sendo o método curativo baseado em técnicas cirúrgicas mucogengivais, como a utilização de enxerto autógeno, ${ }^{11} \mathrm{o}$ qual é muitas vezes contra-indicado pela ausência de área doadora, ou de enxerto com matriz dérmica acelular, ${ }^{18}$ realizado com o intuito de diminuir o tempo cirúrgico assim como o desconforto pós-operatório.

Uma alternativa para o tratamento da recessáo é o método preventivo, ${ }^{11}$ que consiste na eliminação dos fatores etiológicos, ou seja, controle da higiene bucal, remoção dos hábitos orais e correção ortodôntica.

Em crianças muito jovens, tem sido observada melhora espontânea com o passar do tempo, pela própria mudança ocorrida com o crescimento e desenvolvimento dos arcos. ${ }^{11,13}$

Tendo em vista a escassez literária com relação às doenças periodontais na infân-

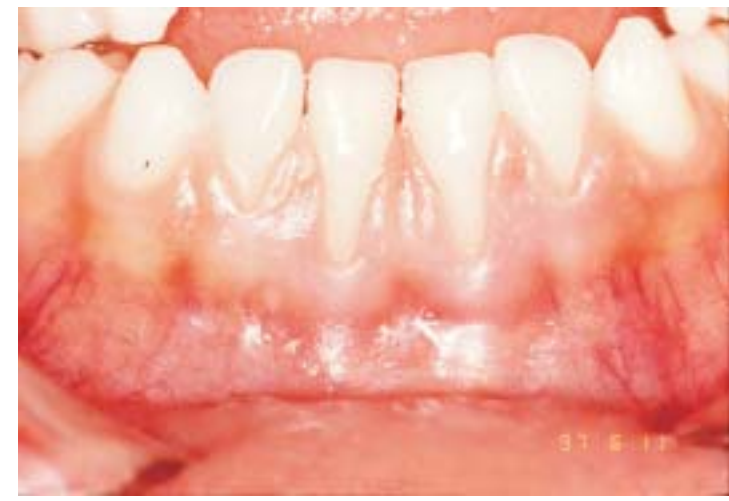

Figura 1 - Recessão gengival extensa na face vestibular dos incisivos inferiores e, em menor grau, nos incisivos laterais inferiores decíduos cia, principalmente abordando problemas mucogengivais na dentição decídua, o propósito deste trabalho é apresentar um caso clínico de recessão gengival na dentição decídua, discutindo aspectos clínicos e conduta terapêutica.

\section{DESCRIÇÃO DO CASO}

A paciente K.F.C., cinco anos de idade, foi encaminhada à clínica de Periodontia da Faculdade de Odontologia de Araraquara - UNESP, para avaliação de um problema mucogengival. Ao exame clínico, constatou-se a presença de recessão gengival extensa na face vestibular dos incisivos centrais inferiores e, em menor grau, nos incisivos laterais inferiores decíduos, conservando-se, entretanto, a altura do tecido interdental (FIGURA 1). O exame do periodonto revelou um tecido gengival com características de normalidade no arco inferior e pequenas alteraçôes inflamatórias no arco superior, porém sem aprofundamento do sulco gengival, apesar da grande quantidade de biofilme dental evidenciada pela coloração de marrom de Bismark. Radiograficamente, verificou-se integridade da crista óssea e germe do sucessor permanente com desenvolvimento normal e compatível com a idade cronológica. A paciente apresentava hábito de sucção de chupeta atípico com interposição da aba inferior na cavidade bucal (FIGURA

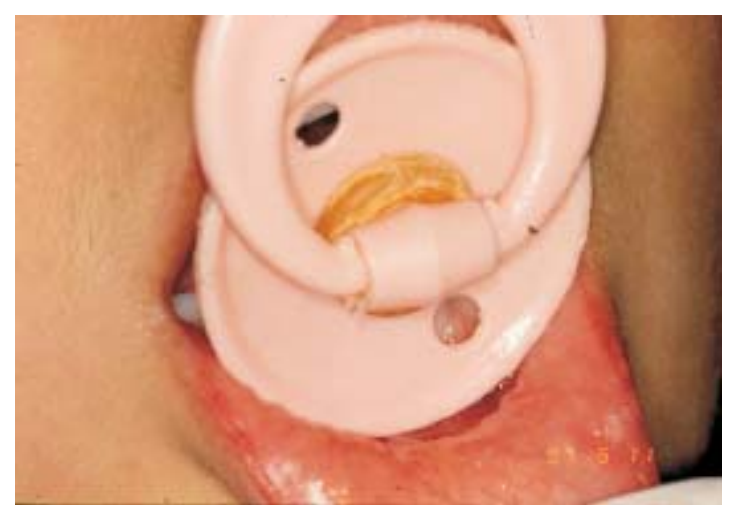

Figura 2 - Interposição da aba inferior da chupeta na cavidade bucal pelo hábito atípico de sucção 
2). Devido à alta frequiência, o hábito desencadeou a mordida aberta anterior e um padrão de deglutição atípico com interposição lingual. Além disso, foi também o fator etiológico principal das recessóes gengivais, pois o posi-cionamento contínuo da aba sobre a margem gengival dos incisivos inferiores levou à migração apical do tecido gengival (FIGURA 3).

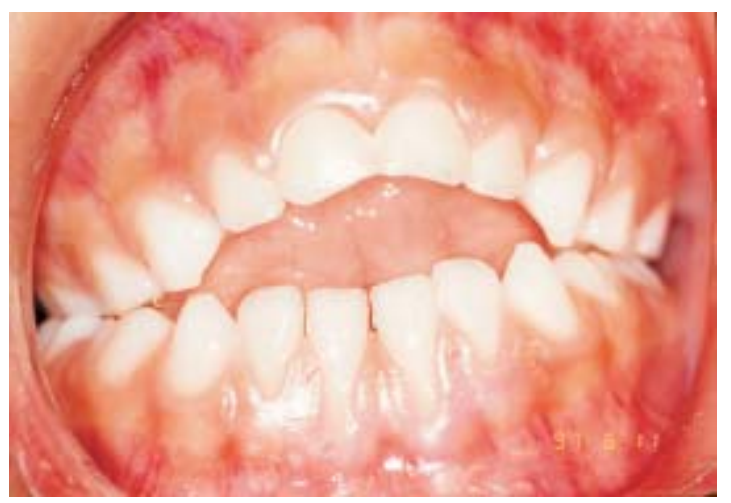

Figura 3 - Presença da mordida aberta anterior e padrão de deglutição atípico com interposição lingual

\section{PLANO DE TRATAMENTO}

Consistiu principalmente em medidas interceptativas que impedissem a progressão das recessôes. Realizou-se o tratamento periodontal básico e a orientação da higiene bucal incluindo a troca da escova dental utilizada para um tipo multitufado, de cabeça pequena e cerdas macias. Isto possibilitou uma higienização efetiva do terço mais apical das recessôes, impedindo, dessa forma, o acúmulo de biofilme dental e o desenvolvimento de um processo inflamatório. A técnica de higiene bem como os procedimentos auxiliares foram ensinados à criança e aos pais/responsáveis, para aceitação das mudanças e sedimentação dos novos hábitos.

Outras medidas de ordem multidisciplinar, auxiliadas por profissionais das áreas de Psicologia e Fonoaudiologia, para remoção do hábito de sucção de chupeta e aprendizado do processo normal de deglutição, também foram necessárias.
Os problemas neurológicos inerentes à paciente impossibilitaram a colocação de um aparelho ortodôntico para evitar a interposição lingual durante a deglutição, ficando submetida apenas a avaliaçóes periódicas para acompanhamento do processo de desenvolvimento da dentição permanente para futura intervenção.

Todos os procedimentos tiveram como objetivo impedir o progresso das recessões gengivais, uma vez que sua correção cirúrgica não é indicada nessa idade, e prevenir futuros problemas mucogengivais nos dentes permanentes sucessores, além de eliminar o quadro de gengivite no arco superior.

Apesar das dificuldades próprias da idade e da condição neurológica, houve boa assimilação e cooperação da paciente e dos responsáveis, resultando em redução do uso da chupeta e, conseqüentemente, da mordida aberta, eliminação do processo inflamatório e controle das recessões.

A paciente foi acompanhada mensalmente para controle do biofilme dental e avaliação da condição gengival na área das recessões.

Os tratamentos concomitantes com os profissionais de Fonoaudiologia e Psicologia resultaram em melhora da fala e da postura psicológica, apresentando-se a criança mais confiante, menos temerosa e mais expansiva, contribuindo para que o hábito de sucção de chupeta estivesse presente apenas na indução do sono.

Após o período de aproximadamente um ano, com o início da substituição dos incisivos inferiores decíduos pelos permanentes, constatou-se a manutenção de pequena faixa de gengiva inserida no dente 41, com o 31 demonstrando extensa faixa de tecido devido ao processo de erupção passiva incompleto (FIGURA 4).

A partir desse momento, a atitude foi expectante com rigoroso controle do biofilme dental, aguardando-se até o término da erupção ativa e passiva para avaliação da necessidade, ou não, de criação de uma faixa de gengiva inserida ou de cobertura de uma possível recessão gengival. 


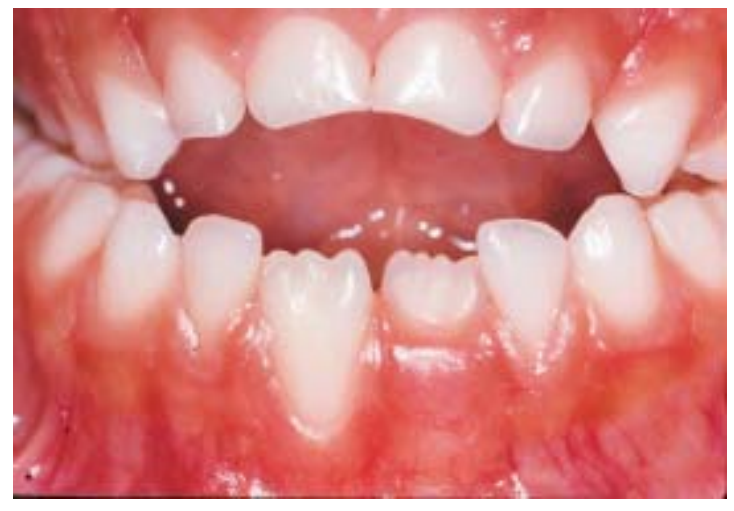

Figura 4 - Após um ano, início da substituição dos incisivos inferiores decíduos pelos permanentes, com manutenção de pequena faixa de gengiva inserida no 41 , e o $31 \mathrm{em}$ erupção incompleta

É importante lembrar que, nessa fase, houve o empenho por parte da família para evitar o hábito de introdução da aba da chupeta na cavidade bucal.

\section{DISCUSSÃO}

A presença de problemas mucogengivais em crianças na primeira infância não é freqüente, ocorrendo na dentição permanente como conseqüência do processo de desenvolvimento, de hábitos bucais, tração de freios e bridas, má posição dentária e outros fatores. ${ }^{1,8,11,12}$

Quando presentes na dentição decídua, as recessôes gengivais estão principalmente associadas a hábitos bucais, como sucção de chupeta e digital, e padrão atípico de deglutição com interposição lingual que conduz muitas vezes à alteração na posição dos dentes anteriores.

Bosnjak e colaboradores ${ }^{8}$ sugerem que os hábitos orais não levam a alteraçôes na dimensão gengival, mas atuam como co-fator no desenvolvimento da recessão gengival, por meio de alteraçôes ósseas e no posicionamento do dente no arco. Segundo Parfitt e Mjör, ${ }^{2}$ e Carranza Jr. e Newman, ${ }^{14}$ o posicionamento vestibularizado do dente no arco altera a estrutura periodontal, a qual se apresenta com altura e espessura reduzidas, predispondo à recessão gengival pela menor resistência à irritação mecâni- ca. Andlin-Sobocki, Marcusson e Persson ${ }^{19}$ observaram que $80 \%$ dos incisivos inferiores com recessão gengival, em crianças de 6 a 13 anos, apresentavam-se em posição vestibularizada no arco. No entanto, demonstraram que esta pode ser freqüentemente reduzida com o tempo, sugerindo que o tratamento curativo talvez não seja necessário. Da mesma forma, Carranza Jr. e Newman ${ }^{20}$ afirmam que a recessão pode ser uma fase transitória na erupção dentária e pode se autocorrigir devido às mudanças na dentição durante o crescimento, favorecendo o alinhamento dentário.

O caso descrito ilustra a presença de recessôes gengivais em dentes decíduos relacionadas ao hábito de sucção de chupeta, presença de mordida aberta e deglutição atípica. Entretanto, apesar de serem extensas, a baixa idade da paciente contra-indicou a correção dessas recessões por técnicas cirúrgicas mucogengivais, pela complexidade das mesmas e ausência de áreas doadoras, ficando o tratamento restrito à eliminação do hábito, correção do padrão de deglutição e manutenção da saúde gengival.

Assim, os procedimentos terapêuticos empregados neste caso visaram a impedir a progressão das recessões, prevenindo o comprometimento estético e funcional da dentição permanente. O controle do biofilme dental foi considerado imprescindível para evitar a associação de um processo inflamatório que aceleraria a migração apical da margem gengival.

Soares e $\operatorname{Vargas}^{17}$ observaram que $66,66 \%$ dos dentes com recessão gengival apresentavam inflamação gengival, concluindo que a placa bacteriana é um fator primordial no desenvolvimento da recessão e que seu controle pode limitar ou mesmo reverter o quadro. Andlin-Sobocki, Marcusson e Persson ${ }^{19}$ também consideraram a inflamação gengival induzida por placa como possível fator etiológico ao verificarem altos escores de gengivite nas recessões analisadas.

Da mesma forma, Powell e Mc Eniery ${ }^{16}$ sugerem que a inflamação gengival por si só pode induzir recessão gengival, e que o processo se acelera pela associação com outros fatores, enquanto Kennedy e colaboradores ${ }^{21}$ demonstraram que, mesmo em áreas de mínima quan- 
tidade de gengiva inserida, o controle da inflamação foi responsável pela manutenção da saúde periodontal, evitando recessão ou perda adicional de inserção.

Apesar de, no presente caso, a paciente não apresentar alterações inflamatórias na região da recessão, como forma preventiva, a técnica de higiene e a escova utilizada bem como os meios auxiliares foram modificados e adaptados à condição clínica e ao grau de coordenação da criança, embora totalmente supervisionados pelos pais/responsáveis.

Entretanto, somente o tratamento periodontal não é suficiente para impedir danos futuros. Antes da substituição da dentição decídua pela permanente, é necessário que se removam os fatores causais desta anormalidade, que, neste caso, consiste no hábito de sucção de chupeta. De acordo com Larsson, ${ }^{22}$ aproximadamente um terço dos succionadores de chupeta posicionam a aba parcialmente interna ao lábio inferior, o que pode prejudicar a dentição, chegando a afetar o osso marginal da região anterior da mandíbula.

As alterações dentárias decorrentes deste hábito que podem estar presentes são protrusão dos incisivos superiores e inferiores, mordida aberta anterior, overjet acentuado, supraversão dos molares e mordida cruzada posterior. Machtei e colaboradores ${ }^{6}$ afirmam que a mordida aberta anterior aumenta a prevalência da recessão gengival e pode estar associada ao alto índice de inflamação gengival relacionado com o selamento labial incompetente e com um aumento da coroa clínica. Com relação às alterações esqueléticas, poderá ocorrer alongamento do arco dentário, rotação anterior do plano nasal e mandibular, inibição do crescimento entre nasio e espinha nasal anterior e inibição do crescimento do processo alveolar anterior. ${ }^{23,24,25}$ Estas alterações podem ter diferentes graus dependendo da época de início, da duração, freqüência e intensidade do hábito e de fatores predisponentes do indivíduo. ${ }^{25}$

Existe ainda uma associação entre hábito de sucção de chupeta e padrão de deglutição atípico. ${ }^{26} \mathrm{O}$ caso aqui relatado representa essa associação, com o paciente apresentando deglu- tição atípica com interposição lingual, o que pode ser um fator agravante da recessão, na medida em que força os dentes anteriores para vestibular, podendo promover reabsorção do osso alveolar nessa região.

Entretanto a remoção do hábito é uma tarefa difícil, uma vez que existe grande envolvimento emocional da criança. ${ }^{27}$ A utilização de aparelhos ortodônticos para auxiliar a remoção do hábito e corrigir os problemas de má oclusão pode ser indicada, desde que o paciente esteja convencido de que a remoção do hábito será em seu próprio benefício e esteja disposto a colaborar; caso contrário, pode-se causar um problema psicológico maior do que o preexistente ou o desenvolvimento de um novo hábito. Os aparelhos mais comumente utilizados para interceptação de hábitos de sucção com deglutição atípica são aqueles que possuem uma grade lingual, que pode ser fixa ou removível, com ou sem reeducador lingual. ${ }^{28,29}$

No presente caso, a paciente não foi cooperadora na confecção do aparelho devido a problemas neurológicos inerentes, tendo sido seguida a orientação psicológica para que se postergasse sua confecção e instalação.

Compreende-se, portanto, que o tratamento das recessôes gengivais na dentição decídua é paliativo e se restringe ao controle desses defeitos, procurando impedir sua progressão, por meio da correção dos hábitos que conduziram ao seu aparecimento, por tratamento ortodôntico, fonoaudiológico, psicológico ou periodontal. ${ }^{6}$ Essas medidas também podem resultar em melhora espontânea da recessão em crianças de pouca idade durante seu crescimento e desenvolvimento.

O tratamento cirúrgico em crianças deve ser adiado, sendo executado apenas se a recessão se mantiver progressiva após a realização do tratamento conservador. ${ }^{11}$

A abordagem terapêutica deve ser multidisciplinar, envolvendo profissionais das áreas de Periodontia, Ortodontia, Otorrinolaringologia, Psicologia e Fonoaudiologia para restabelecer no paciente as condições de normalidade funcional e estética. 


\section{CONCLUSÓES}

Do exposto, pode-se concluir que:

a) As recessōes gengivais na dentição decídua são freqüentemente associadas a hábitos bucais.

b) A correção desses defeitos é limitada pela idade do paciente, devendo ser controlados para evitar o comprometimento da dentiçáo permanente. c) Os hábitos associados e desencadeadores devem ser eliminados, e novos padrōes devem ser estabelecidos para recuperação e manutenção da saúde periodontal.

d) O tratamento é multidisciplinar, envolvendo profissionais de diferentes áreas e a indispensável colaboraçẫo dos pais.

\title{
Gingival recession in the deciduous dentition: a case report
}

\begin{abstract}
The authors report an uncommon occurrence of a clinical case of gingival recession in the deciduous dentition. They discuss the clinical aspects and the determinant and predisposing factors for the forthcoming of the mucogingival problem as well as the treatment procedures with interceptive and preventive methods.
\end{abstract}

Keywords: Gingival recession. Dummy sucking habit. Posterior crossbite. Anterior openbite. Swallowing pattern.

\section{REFERÊNCIAS}

1 STONER, J.E.; MAZDYASNA, S. Gingival recession in the lower incisor region of 15 year old subjects. J. Periodontol., Chicago, v.51, n.2, p.74-76, Apr. 1980.

2 PARTIFF, G. J.; MJOR, I. A. A clinical evaluation of local gingival recession in children. J. Dent. Child., Fulton, v.31, p.257-262, 1964.

3 YOUNES, S. A. E. S.; ANGBAWI, M. F. E. Gingival recession in the mandibular central incisor region of Saudi schoolchildren aged 10-15 years. Community Dent. Oral Epidemiol., Copenhagen, v.11, p.246249, Jan. 1983.

4 SUSIN, C.; AZEVEDO, M. P. Prevalência de recessão gengival em escolares e sua relação com o estado inflamatório gengival. Periodontia, Fortaleza, v.6, n.1, p.41-45, jan./jun. 1997.

5 HARRISON, R. L. et al. The association of simple anterior dental crossbite to gingival margin discrepancy. Pediatr. Dent., Chicago, v.13, n.5, p.296-300, Sept./Oct. 1991.

6 MACHTEI, E. E. et al. Anterior open bite and gingival recession in children and adolescents. Int. Dent. J., London, v.40, p.369-373, 1990.
7 RAMFJORD, S. P. Orthodontics and periodontal prophylaxis. In: HOLS, E.; ZACHRISSON, B. V.; BALDAUF, A. Orthodontics and periodontics. Chicago: Quintessence, 1985. p.113-125.

8 BOSNJAK, A. et al. Incidence of oral habits in children with mixed dentition. J. Oral Rehabil., Oxford, v.29, p.902-905, 2002.

9 TATAKIS, D. N.; MILLEDGE, J.T. Severe gingival recession in trisomy 18 primary dentition: a clinicopathologic case report of self inflicted injury associated with mental retardation. J. Periodontol., Chicago, v.71, n.7, p.1181-1186, July 2000.

10 SEPET, E. et al. Factitial (self-induced) gingival disease: four case reports. Quintessence Int., Berlin, v.32, n.8, p.762-765, 2001.

11 KARIMBUX, N.; WARA ASWAPATI, N. Defeitos mucogengivais e seu tratamento. In: BIMSTEIN, E. et al. Saúde e doenças periodontais e gengivais: crianças, adolescentes e adultos jovens. São Paulo: Livr.Ed.Santos, 2003. p.49-57.

12 GORMAN, W. J. Prevalence and etiology of gingival recession. J. Periodontol., Chicago, v.38, p.316-322, 1967. 
13 SANTOS-PINTO, L. A. M. et al. Fenestration gingival defect in erupting permanent mandibular incisors: a case report. Quintessence Int., Berlin, v.29, p.239-242, 1998.

14 CARRANZA JR., F. A.; NEWMAN, M. G. Periodontia clínica. 8.ed. Rio de Janeiro: Guanabara Koogan, 1997. cap.17, p.235-245.

15 GEIGER, A. M. Mucogingival problems and the movement of mandibular incisors: a clinical review. Am. J. Orthod., St.Louis, v.78, p.511-527, 1980.

16 POWELL, R. N.; MC ENIERY,T. M. Disparities in gingival height in the mandibular central incisor region of children aged 6-12 years. Community Dent. Oral Epidemiol., Copenhagen, v.9, p.32-36, 1981.

17 SOARES, M. R.; VARGAS, A. M. D. Prevalência de recessão gengival inflamatória em crianças de escola pública de Belo Horizonte (MG). R. CROMG, Belo Horizonte, v.7, n.3, p.157-163, set./dez. 2001.

18 WAGSHALL, E. et al. Acellular dermal matrix allograf in the treatment of mucogingival defects in children: illustrative case report. ASDC J. Dent. Child., Chicago, v.69, n.1, p.39-43, Jan./Apr. 2002.

19 ANDLIN-SOBOCKI, A.; MARCUSSON, A.; PERSSON, M. 3-year observations on gingival recession in mandibular incisors in children. J. Clin. Periodontol., Copenhagen, v.18, p.155-159, 1991.

20 CARRANZA JR., F. A.; NEWMAN, M. G. Periodontia clínica. 8.ed. Rio de Janeiro: Guanabara Koogan, 1997. cap.21, p.291-295.
21 KENNEDY, J. E. et al. A longitudinal evaluation of varying widths of attached gingival. J. Clin. Periodontol., Copenhagen, v.12, p.677-675, 1985.

22 LARSSON, E. De initiala napp-och finfersugningsvanornas frekvens. Tandlakartidningen, Stockholm, v.75, p.695-699, 1983.

23 LARSSON, E. Dummy and finger sucking habits with special attention to their significance for facial growth and occlusion: effect on facial growth and occlusion. Sven. Tandlak. Tidskr., Stockholm, v.65, p.605-634, 1972.

24 CHAN, C. et al. Estudo cefalométrico dos efeitos esqueléticos e dentários de hábito persistente de sucção de chupeta. R. Odontol. UNESP, Marília, v.25, p.171-182, 1996.

25 POPOVICH, F. Prevalence of sucking habit and its relationship to malocclusion. Oral Health, Don Mills, v.57, p.498-505, 1967.

26 MELSEN, B.; STENSGAARD, K.; PEDERSEN, J. Sucking habits and their influence on swallowing pattern and prevalence of malocclusion. Eur. J. Orthod., Oxford, v.1, p.271-280, 1979.

27 ANKE, B. Prolongation of the sucking habit as a result of emotional disturbances. Sven. Tandlak. Tidskr., Stockholm, v.65, p.309-316, 1972.

28 PETERSON, J. E.; SCHNEIDER, P. E. Oral habits: a behavioral approach. Pediatr. Clin. North Am., Philadelphia, v.38, p.1289-1307, 1991.

29 ALMEIDA, R. R. A.; URSI, W. J. S. Anterior open bite. Oral Health, Don Mills, v.80, p.27-31, 1990. 